\title{
EPISTEMIC LEVELS, THE PROBLEM OF EASY KNOWLEDGE AND SKEPTICISM
}

Tito Flores*

\begin{abstract}
RESUMO - O problema do conhecimento fácil tem sido definido na literatura epistemológica contemporânea com um problema que nasce de duas formas distintas. O propósito deste ensaio é mostrar que essas supostas maneiras diferentes de gerar o mesmo problema em verdade originam dois problemas distintos, que requerem respostas distintas. Um deles está relacionado à aquisição fácil (inaceitável) de conhecimento de primeira-ordem e o outro à aquisição fácil (inaceitável) de conhecimento de segunda-ordem. Além disso, é apresentada a maneira como o infinitismo, a teoria epistêmica segundo a qual as razões que justificam uma opinião devem ser infinitas em número e nãorepetidas, pode lidar com cada um desses problemas.
\end{abstract}

PALAVRAS-CHAVE - ceticismo. Problema do critério. Princípio do fechamento epistêmico. Problema do conhecimento fácil.

\begin{abstract}
The Problem of Easy Knowledge has recently been defined as arising in two different forms: one connected with some version of the epistemic closure principle and the other with bootstrapping. This essay shows that these supposed two forms actually generate two quite different problems. One of them is related with the supposed easy (unacceptable) acquisition of firstorder knowledge, and the other with the supposed easy (unacceptable) acquisition of second-order knowledge, each of them requiring different solutions. It is also presented how Infinitism, the view that the structure of justificatory reasons is infinite and non-repeating, can deal with these two different challenges.
\end{abstract}

KEYWORDS - Skepticism. Problem of the Criterion. Closure Principle. Problem of Easy Knowledge. Epistemic Level Confusion.

The so-called Problem of Easy Knowledge has recently become a great focus of interest in epistemology. This is so, mainly, I think, due to Stewart Cohen's paper "Basic Knowledge and the Problem of Easy Knowledge". ${ }^{1}$

* Doutor em Filosofia pela Pontifícia Universidade Católica do Rio Grande do Sul.

1 See COHEN, Stewart. "Basic Knowledge and the Problem of Easy Knowledge". In: Philosophy and Phenomenological Research , 65 (2002), p. 309-329; "Why Basic Knowledge is Easy Knowledge". In: Philosophy and Phenomenological Research, 70 (2005), p. 417-430.

\begin{tabular}{|l|l|l|l|l|l|} 
VERITAS & Porto Alegre & v. 54 & n. 2 & maio/ago. 2009 & p. 109-129 \\
\hline
\end{tabular}


Since then, much has been said about this problem and different solutions have been offered. ${ }^{2}$

Despite Cohen's claims that "the Easy Knowledge Problem arises in two related ways", ${ }^{3}$ there is neither one problem arising in two distinct manners nor a new epistemological problem being presented. Rather, what Cohen calls "the problem of easy knowledge" seems to be more the result of a couple of misunderstandings, a combination of a high degree of epistemic level confusion and the renaming of very ancient philosophical challenges.

In the course of this paper I will try to show that Cohen is dealing with not one, but two quite different problems. One problem has to do with an unacceptable way to come to know that we know things (and that looks pretty much like one alternative to resolve what in the pyrrhonian tradition has been called "the problem of the criterion"). The other involves our capacity to reason from appearances in order to establish what things really are.

\section{Epistemic levels}

Level confusion is not at all a new phenomenon in epistemology. ${ }^{4}$ I do not intend, though, to examine it in detail. I'm concerned with epistemic levels only to the extent it may cause difficulties for understanding the easy knowledge problem.

The first epistemic level, the level of first-order knowledge, is pertinent to our discussion as it deals with the conditions according to which a person $S$ can know that some proposition $p$ is true. This level could be understood as the most elementary one, the object of the larger part of epistemological parley.

When we get through the first level we do no more than take into account the conditions according to which a subject $S$ knows that a proposition describing empirical events is true.

The first level in epistemology epitomizes the relation between a person's beliefs about empirical events and the content of these beliefs.

2 E.g. MARKIE, Peter. "Easy knowledge". In: Philosophy and Phenomenological Research, 70 (2005), p. 406-416; NETA, Ram. "A contextualist solution to the problem of easy knowledge". In: Grazer Philosophische Studien. Internationale Zeitschrift für Analytische Philosophie, 69 (2005), p. 183-206; VAN CLEVE, James. "Is knowledge easy - or impossible? Externalism as the onlyalternative to skepticism". In: LUPER, Steven (ed.). The skeptics: contemporary essays, 2003, p. 45-49; BLACK, Tim. "Solving the easy knowledge problem". In: The Philosophical Quarterly, 58 (2008), p. 597-617.

3 See COHEN, Stewart, 2002, p. 312.

4 See ALSTON, William. "Level confusions in epistemology". In: Midwest Studies in Philosophy, (1980), p. 135-150. 
In other words, the first level is confined on the affairs concerning the suitable connection between the beliefs and the truth, regardless the believer's awareness of her believing, knowing or capturing the truth.

All Gettier cases, for example, are reduced to the epistemic first level since they are intended to show nothing else than that mere true justified belief does not count as (first order) knowledge. The Gettier cases deal with first order knowledge as they tackle only the subject's oblivious competence in avoiding the accidental coincidence between justification and truth, i.e. the subject's capacity of knowing some proposition that describes the world.

The second level, the level of second-order knowledge or metaknowledge, on the other hand, concerns the conditions according to which a person $S$ can know that she knows some proposition $p$ is true. Now the picture changes radically. To begin with, one of the necessary conditions for second-order knowledge is first-order knowledge since it is not possible for any subject to know that she knows $p$ is true if she doesn't know $p$ is true in the first place. The requirements for second order knowledge may very well include some (or even all) conditions for first order knowledge, but by necessity they will never be the same.

At the second level in epistemology we'll emphasize the subject's reflections on her knowing - or believing - that a proposition describing empirical events is true.

One way to describe the second level in epistemology is to say that it embodies the relation between a person who has beliefs about empirical events and her own believing. This relation brings in the person's reflection on her specific epistemic condition. The second level is, in one way or another, related to the affairs concerning the connection between beliefs and truth as well, but in this case regarding the awareness of the believer on her believing, knowing or capturing the truth.

Another way to figure out the epistemological meta-level is to say that this level stands for the justification of knowledge claims. So, when we talk about meta-justification, we are talking about the justification of what we believe to be justified.

As a consequence, when we assume the conditions for first and second-order knowledge are equal, or we do not see the distinction between these two levels, we incur in epistemic level confusion.

The conclusion of any particular theory of knowledge may require a particular articulation between first and second epistemic levels. This doesn't mean, however, that we are free to mix up the levels, since it is not clear at all that as soon as a person knows $p$ is true she is automatically in the position to know that she knows $p$ is true. That's one of the main reasons why we always have to distinguish between levels clearly. 
Also depending on theory, huge differences in terms of the attributed importance to the levels will appear. Even while recognizing the possibility for second order knowledge, some epistemological theories are consistent with the idea that second order knowledge is simply not too important - at least, not essential. Accordingly, once the right conditions for first order knowledge are determined, the foremost job in epistemology is done and all the rest can be kept, with no cost whatsoever, in the realm of skepticism. These sorts of epistemological theories may end up having no qualms to attribute first order knowledge to anyone capable of meeting these conditions, like very young children, animals and virtually anything that may be capable of believing. ${ }^{5}$

On the other side of the spectrum, some theories will state that if a person knows $p$ is true but doesn't know that she knows $p$ is true, she will find herself with empty hands. This is so, according to these theories, because the important philosophical aspects of knowledge are linked with some sort of appreciation that we know things. This way, knowing without knowing that one knows amounts to pretty much nothing. Expectedly, these theories will not be eager to concede knowledge to neither dogs nor children. ${ }^{6}$

Different theories of knowledge will define in their own terms not only its subject of analysis but also the importance of theirs and other possible subject matters. In the same way a particular theory will define its scope and determine what is philosophically relevant to be analyzed and defined.

I believe that some of the recent epistemological debate about two senses of knowledge has to do with the difference about epistemic levels ${ }^{7}$. It has been said that one sense of "knowledge", less philosophical and more mundane, could be completely analyzed in the terms suggested by some externalist-type theories. In contrast, the sense of "knowledge" more articulated and intelligent, the one menaced by skepticism, runs off from any externalist examination and could be grasped only by internalist-type theories.

This debate shows, again, the importance of keeping the distinction between epistemic levels up and clear. Even if we decide to break epistemology in two, each part dealing with a different sense of

See Fred Dretske, Perception, Knowledge and Belief, 2000, p. 23.

6 E.g. Peter Klein, Human Knowledge and the Infinite Regress of Reasons, in: Philosophical Perspectives, 13 (1999), p. 297-325; and Keith Lehrer, Theory of Knowledge, 2000, p. 55.

7 See Ernest Sosa, Two False Dichotomies: Internalism/Externalism and Foundationalism/Coherentism, in: Walter Sinnott-Armstrong (ed.), Pyrrhonian Skepticism, 2004, p. 146-160. 
knowledge, we still can't forget that these two senses are but two distinct levels of knowledge, one exclusively portraying the connection between one's beliefs and the truth and the other depicting the appreciation of the believer about this supposed connection.

It seems quite reasonable to me to believe that part of the misunderstandings regarding skepticism - particularly pyrrhonian skepticism - are due to the fact the epistemic levels are not clearly distinguished. As we'll see a little latter, Sextus Empiricus himself seems to be one of the main sources for epistemological level confusion. Once we realize that some of the skeptical challenges are directed to meta-knowledge, as it seems to be the case with the problem of the criterion, and others to first-order knowledge, as it seems to be the case with the epistemic regress brought about by Agripa's trilemma, we'll not only have a better understanding over skepticism, but also will be in a better position to deal with them.

\section{The closure principle}

As it was said at the beginning, according to Cohen "the Easy Knowledge Problem arises from two related ways". ${ }^{8}$ As I understand it, it means that there exist two ways to raise the same problem. One of them is via bootstrapping; the other one is through the closure principle. We'll see that the problem with bootstrapping has to do with illegitimately acquiring second-order knowledge. But first, we will examine what kind of problem, and what kind of easy knowledge, may emerge from the closure principle.

When we consider the closure principle under the strict optic of epistemology, all we say is that knowledge is "closed" under logical implication. This roughly means that if we know some proposition $p$, and this proposition logically implies another proposition, $q$, we also know $q$. The idea is that we can increase the set of proposition we know to the extent of what is implied by this original set of known propositions.

I do not intend to offer a flawless formulation of the closure principle here. Rather, I want to discuss a few points that will give us a clear idea about what is epistemologically important about the closure principle. I think that, at least for now, more important than reaching an unblemished presentation of the closure principle is to understand what is behind this principle and why sometimes it is thought that we will be better off rejecting it.

In a first attempt, the closure principle could be expressed like this: if a person, $S$, knows $p$, and $p$ implies $q$, then $S$ knows $q$.

8 See Stewart Cohen, 2002, p. 312. 
Even though this first formulation captures the key idea behind the closure principle, we can add to it some clause that closes the closure principle under the realm of $S^{\prime}$ 's conscience. This way, we can avoid unnecessary complications that we'll go over briefly. So we can reformulate the closure principle like this: if a person, $S$, knows a proposition $p$, and $S$ implies $q$ from $p$, then $S$ knows $q$.

Depending on the way we formulate the closure principle, we can make it either obviously false or even more strikingly appealing. We can see that when we change the predicate that works as its operator. If we say, for example: if $p$ is true and $p$ implies $q$, then $q$ is true, the principle will maintain the same structure as epistemic the closure principle but will appear to be much beyond reasonable complains. This is so because nobody will be ready to deny that the predicate "truth" is closed under logical implication.

However, if we change the epistemic operator, "to know" for "to believe" things will seem completely different. If we formulate the principle like this: if a person, $S$, believes a proposition $p$ and $p$ implies $q$, then $S$ believes $q$, the closure principle will be bluntly false. This is so because, as a matter of fact, our believing is not closed under logical implications.

It is possible to point out problems with closure based on the inapplicability of closure to believing. For if knowledge requires, among other things, a belief and the believing is not closed under logical implication, so knowledge cannot be closed under implication as well.

This is probably true, but if we continue in this direction we'll end up lost in epistemologically irrelevant problems. The same happens when we dispute over the fact that $S$ must somehow "see", or perform, the logical implication between $p$ and $q$. All these non-epistemic problems with the closure principle can be settled by adding some restrictions and constraints over the applicability of the principle. In my opinion, this is a fine and important task. However, we can keep all these additional complications aside.

The important aspect is this: what is distinctively relevant about knowledge, that of which our knowledge is made of, epistemic justification or whatever it may be, seems indeed to be closed under logical implication. There is something deeply intuitive about the fact that if I have epistemic justification for believing a proposition that describes empirical events - even if I do not have the belief itself already formed and this first proposition logically implies another one of the same type, I do not lose any justification for believing in the implied proposition. In this respect, the closure principle poses that, in the same way as truth, something important about our knowledge is preserved along with logical implication. 
It is worthwhile to mention that one reason that has been put forth to reject the closure principle is the alleged fact that it would lead to skepticism. In the one version of Cartesian (or academic) skepticism an instance of the closure principle is used as premise for the conclusion that knowledge in unattainable.

The skeptical argument goes like this: 1) If I know some ordinary proposition $p$ - that I'm in Rosario, for example - then I know that $q$, a proposition that is inconsistent with $p$, but that could be true regardless the empirical evidence I have for $p$ - that I'm in Philadelphia dreaming that I'm in Rosario, for example - is false; 2) I don't know q is false - I don't know that I'm not in Philadelphia dreaming that I am in Rosario; therefore 3) I don't know p - I don't know I'm in Rosario.

I will not discuss the skeptical argument in any detail now. I just want to point out that the first premise is an instance of the closure principle and the skeptical argument can be easily generalized in order to include any descriptive proposition like $p$.

Since the argument is valid, the only way to reject the skeptical conclusion established in 3 is to refuse one of the premises. If the chosen premise is 2 , the dispute will be directed over the closure principle.

That strategy for dealing with this type of skeptical argument is one of the main reasons for rejecting the closure principle. I think, however, that that strategy is misguided. This is so because the closure principle is neutral regarding the skeptical conclusion. It can straightforwardly be seen once we change the form of this kind of skeptical argument from a modus tollens to a modus ponens. This way we'll observe that the potentially skeptical premise is 2 , not 1 . Differently from the first premise, it is the second one that hides regulations on our evidences to believe descriptive propositions, and it is this sort of evidential restrictions that, bottom-line, makes the skeptical conclusion possible.

If we keep the first premise, and consequently do not quarrel over the closure principle, but change the second one, we can have an argument like this: 1) If I know some ordinary proposition $p$ - that I'm in Rosario, for example - then I know that q, a proposition that is inconsistent with $p$ - hat I'm in Philadelphia dreaming that I'm in Rosario, for example - is false; 2) I do know that $p$ is true; therefore 3) I do know that $q$ is false - I do know that I'm not in Philadelphia dreaming that I'm in Rosario.

The latter argument shows that the closure principle can be used for skeptical and non-skeptical purposes as well. Hence, it is false that there is something in closure that motivates skepticism.

In the following discussion no details about the closure principle will be necessary. As we will see, the closure principle has little to do with the kind of troubles Cohen envisions with his easy knowledge problem 
and a preliminary understanding of the closure principle will be enough for this purpose.

\section{Closure and easy knowledge}

Cohen's argument against the closure principle has a form of a reductio ad absurdum. Since we have unacceptable results from using the closure principle, we should reject it. According to Cohen, the closure principle would help us to increase our knowledge however in an unacceptable fashion, since the kind knowledge we can acquire from using the closure principle is "easy".

He describes his concerns as follows:

"If I know the table is red on the basis of its looking red, then it follows by the closure principle that I can know that it's not the case that the table is white but illuminated by red lights. Presumably, I cannot know that it's not the case that the table is white illuminated by red lights, on the basis of the table's looking red." 9

Apparently, the problem is that it would be all too easy to come to know that the table is not white but illuminated by red lights on the basis of its red looking. The point for him, it seems so, is to try to show that there is something wrong with the closure principle, something that would allows us to know that the table is not white but illuminated by red lights on the basis of the table's looking red. It's very important to notice that Cohen is arguing that the reason for rejecting the closure principle is that this principle allows us to come to know the table is not white but illuminated by red lights on the basis of its looking red.

This rejection of the closure principle is anchored on the indisputable fact that if the table were not red but rather white illuminated by red lights, the table would continue to look red. In this case, we would have a white table that looks red and, according to him, the closure principle would allow us to conclude, on the basis of the red looking of the table, that the white table is not really white but red.

What Cohen calls, then, "easy" is our knowledge that the table is not white but illuminated by red lights, and what makes things appealing is that this easy knowledge can be attained because of closure, a very popular principle in epistemology.

We should keep in mind at this moment that (1) Cohen thinks that the closure principle should be rejected for it permits us to conclude that one table that looks red is not white but illuminated by red lights; that item of knowledge is illegitimate easy knowledge and (2) whether Cohen

9 See Stewart Cohen, 2002, p. 310. 
is misguided or not, that item of illegitimate easy knowledge is clearly first-order knowledge.

In "Closure Matters", ${ }^{10}$ Peter Klein argues that the question is rather whether it is possible to know that the table is red by reasoning from the table looks red, and not the following move - which involves the closure principle - from the table is red to the table is not white but illuminated by red lights.

If we consider the three following steps, (1) it looks red, (2) it is red, and (3) it is not white but illuminated by red lights, the controversial move is from the first step to the second, and not from the second to the third, the one that actually includes the closure principle.

This is so because if I can know that the table is red on the basis of its looking red, there is no problem with the inference from "it's red" to "it's not white but illuminated by red lights". Closure just allows us to conclude: "the table is not white but illuminated by red lights" from "the table is red". The problem here is to decide if it is possible (and, of course, specify under which conditions this would be possible) to reason from "the table looks red" to "the table is red" and not the further step, when we use the closure principle to increase our knowledge, from "it's red" to "it's not white but illuminated by red lights".

If that is right, the only easy knowledge problem is that it is not easy to see what could be the problem with closure in this context. The idea of a reductio argument showing that we have problems with the closure principle ignores the most important point: the problem pointed out by Cohen is rather related to deciding how much a theory will allows us to trust in the way things appear to us.

Cohen's idea, that the closure principle should be rejected because it would allows us to conclude that something is not white but illuminated by red lights on the base of the red looking of the thing, seems just wrong. This is so because closure does not permit that. Closure leads to the conclusion that something is not white but illuminated by red lights from "the thing is red," not from "the thing looks red." The epistemological discussion here has little to do with the closure principle, but rather with whether we can know the table is red based on the red looking of the table.

The only possible easy knowledge is that the table is red based on the table's looking red. Cohen's insistence on the third part of the argumentthe part that goes from "it's red" to "it's not white but illuminated by red lights" - only shows that there may be something wrong with the

10 Cf. Peter Klein, Closure Matters: Academic Skepticism and Easy Knowledge, in: Philosophical Issues, 2004, p. 165-181. 
first step of the argument - the step that goes from "it's look red" to "it's red". But this, again, shows nothing epistemically wrong about the closure principle.

In pointing out that there should be something wrong with the closure principle in the acquisition of illegitimate easy knowledge, Cohen somehow misplaced the real philosophical discussion and, at the same time, he called attention to his easy knowledge problem. Despite of other differences of opinions, the real disagreement between Klein and Cohen is much less about the closure principle than it is about the first step in the reasoning, the one that goes from "it looks red" to "it's red".

Klein claims that there is nothing incorrect, in any respect, with the closure principle. However, much more interesting in this context is that he seems to think that the conclusion that something is red on the basis of its red looks may be, under certain circumstances, just a fine way of reasoning. The red appearance of a table can be seen, according to Klein, as a clue about its redness, since, he claims, things that are red used to have this red appearance. ${ }^{11}$

It could be said that we may know the table is red on the basis of its looking red if we have no defeaters. So, the red appearance of the table may be an appropriate way to come to know the table is red, under certain circumstances - namely, no defeater circumstances. Klein assumes that the red appearance of the table, under the no-defeaters circumstance, is a good indication of the redness of the table - because red things have this "tendency" to appear red. How does he know that red things have a tendency to appear red? Well, that's another story. What is essential now is that he is trying to provide a rationale according to which we can reason from "the table looks red" to "the table is red".

If we assume for a minute that Klein is in the right path when he says that the controversial move from "it's look red" to "it's red", but this move may not be problematic at all, it would be odd to expect him to blame the closure principle for any sort of expansion of our knowledge. For if one sees nothing absurd in going from "the table looks red" to "the table is red", one will be ready to accept the conclusion "the table is not white but illuminated by red lights".

On the other hand, Cohen seems to think that we can't possibly know that the table is red based on its red appearance. He seems to be bothered with the fact that we have no reason to think that red things have tendencies to look red. However, stressing the last part of the argument, the part where the closure principle plays a role, can only make case for

${ }_{11}$ Id. ibid. p. 170. 
the implausibility of the first step of the argument. The best that could be said would be something like this: "look, we can't accept to go from "the table appears red" to "it is red" because once we do that we may also go, using the closure principle, to "the table is not white but illuminated by red lights". But, again, the last part of the argument is just a freeloading discussion derived from the main disagreement exposed in the first part, the one in which we reach implications from "it is red".

Thus, the real disagreement is about whether we can know things are based on the way they look, a disagreement as old as philosophy itself, not about the closure principle. What Cohen seems to do is to use the closure principle to try to make a stronger case about the impossibility of knowing the table is red based on it's red appearances.

It's not my purpose to discuss here whether we can know how things are based on the way they appear to us - that would be way too much for this paper. What is important at this time is to realize that the so-called problem of easy knowledge neither involves closure nor presents any epistemological novelty. There is nothing in the problem of easy knowledge that even calls for a defense of the closure principle as well, since the epistemological question at stake does not involve the closure principle. The only "easy" thing is that is too "easy" to know how things are based on the way things look and not the logical consequences that follow from our knowledge the way things are, which does involves the closure principle.

Wherever this discussion ends, what is decisive here is the fact that all knowledge implicated so far cannot be considered, by any means, second-order knowledge. Even if the analysis of this part of Cohen's problem of easy knowledge is wrong, there is no possible way we could consider the easily acquired knowledge in the case involving the closure principle second-order knowledge. That is important for in what follows we'll see that the other way the problem of easy knowledge arises relates to a very different kind of knowledge, one kind that involves knowledge of knowledge claims.

\section{Bootstrapping and easy knowledge}

The starting point of what is now called "problem of easy knowledge" was aimed to be a criticism against some forms of externalism. This seems to have been one of Fumerton's points in "Metaepistemology and Skepticism" and, more recently, in Vogel's "Reliabilism Leveled". We could say that in both cases the objection against externalism was based on the idea that theories like Reliabilism would permit what was called "bootstrapping". 
Bootstrapping was considered then a strongly counterintuitive strategy. To sum up the idea, bootstrapping serves to transform the belief that results from a process of belief formation into the very proof of the reliability of that process.

We can start thinking of bootstrapping through the following example: Michael is driving his car and then he watches the gas gauge's needle. The gauge's needle says that the tank is full. Then, he comes to believe that the tank is full. This belief is based on a process supposedly quite reliable, the gauge's needle indicating that the tank is full. From his belief that the tank is full he comes to believe that the gauge is reliable. Now, he is basing the belief about the reliability of the gauge in another belief, which results from the pure observation of the gauge's needle. In doing so, he comes to know that he knows the tank is full, since he now knows the gauge is reliable. The question is: what is the problem with that?

The problem is that the same strategy could be used even if the gauge was broken. Of course, if the gauge were broken it would seem wrong to allow using a belief that is formed from what the gauge's needle indicates to support a belief about the reliability of the gauge. In both cases, when the gauge's needle is working well and when the gauge's needle is broken, the strategy to bootstrap is the same, but the results are quite different - in one case he knows that the tank is full, but in the other he doesn't. The problem with bootstrapping is that we will get the same result "the gauge is reliable" independently of the reliability of the gauge. That is the reason we must refuse bootstrapping. Thus, bootstrapping delivers second-order knowledge we actually do not have. ${ }^{12}$

The gas tank example is original from Michael Williams's "Unnatural Doubts". The example emerges precisely from a discussion about externalism. Williams states the same conclusion although only thinking on externalism. According to him, "It is perfectly true that I do not learn that the gauge is working properly simply by learning that the tank is full. But what I do learn, that the tank is full, does not entail what I don't, that the gauge is working properly. If the needle is stuck on ' $F$ ', the tank may or may not be full. What is true is that, in particular circumstances, I may have no way of distinguishing the case in which my belief that the tank is full amounts to knowledge from that in which, even if it happens to be true, it does not". ${ }^{13}$ So, the problem with bootstrapping is that we justify a knowledge claim in a vicious way.

12 For a detailed version of bootstrapping cf. Tito Flores, Infinitism, knowing that one knows and the problem of the criterion, in: Veritas, 50 (2005), p. 109-128.

13 Cf. Michael Williams, Unnatural doubts, p. 347. 
The feature that appears to permit bootstrapping would lie in the very core of reliabilism: we could come to know some proposition, $p$, using some reliable method, $m$, with no necessity for us to either know or to be justified in believing (or to have some justification for believing or even identify the method used) the method used were in fact reliable.

In "Externalism and Skepticism", Michael Bergman pointed out that bootstrapping could be a problem not only to externalist theories like reliabilism, as was the original idea, but to internalist theories as well. Cohen in his "Basic Knowledge and the Problem of Easy Knowledge" perhaps made this point even more explicit.

Cohen claimed that the problem of easy knowledge threatens all theories that adopt a "basic knowledge structure". By Cohen's definition, a basic knowledge structure is one that permits that "a belief source can deliver knowledge prior to one's knowing that the source is reliable and hold that reliability knowledge is based on basic knowledge". ${ }^{14}$ He then claimed that, in principle, a Basic Knowledge Structure could shape not only externalist theories but also internalist ones.

This idea seems quite exciting. The intended criticism seems to be directed less toward some possible distinction between internalism and externalism in epistemology and more toward the following, and more interesting, question: should any epistemological theory assume that the individual's awareness of her own evidential basis plays a decisive role in the justification of whatever beliefs the individual has?

One of Cohen's merits is the way in which he unifies the criticism for both externalism and internalism. According to him, many externalist as well as internalist theories do not accept what he calls KR Principle. This principle states that: "a potential knowledge source $\mathrm{K}$ can yield knowledge for $S$ only if $S$ knows K is reliable". ${ }^{15}$

Of course, despite the vocabulary used, such a principle will suit any sort of internalist theory. KR principle can be read like this: a potential evidence E can justify a belief B for $S$ only if $S$ knows (or has evidence) $\mathrm{E}$ is good evidence for $\mathrm{B}$. The main idea $\mathrm{KR}$ principle conveys is that the mere fact that $\mathrm{E}$ is good evidence, or that source $\mathrm{K}$ is reliable, isn't sufficient for $S$ to be justified, or to know, some proposition on the basis of that evidence or knowledge source. For using a belief that results from certain process to prove the reliability of that process is equivalent of using a belief $p$, that is justified by the reason $r$, to show that $r$ is a good reason to believe $p$. Such a move is possible because, according to some

14 Cf. Stewart Cohen, Why Basic Knowledge is Easy Knowledge, op. cit., p. 311.

15 Cf. Stewart Cohen, Basic Knowledge and the Problem of Easy Knowledge, op. cit., p. 309. 
internalist theories, it is not necessary for $S$ to have justification to believe that $r$ is, in fact, a good reason to believe $p$ in order to have justification to be believe $p$ on the basis of $r$ in the first place.

As I think is clear, when we have a true belief that results from reliable method of belief formation, such belief can be prized as "knowledge". And when we know the reliable method used is in fact reliable, we know that we know that proposition. In a passage from Goldman's "Epistemology and Cognition", that says, "to know that we know we would have to know that we use reliable processes of belief formation". ${ }^{16}$

In denying $\mathrm{KR}$ principle, a theory assumes a basic knowledge structure. Consequently, a principle like KR would be assumed just for those theories according to which it is impossible to be justified - or to know something - unless we have some justification that the reasons, or methods of belief formation, we use are epistemically appropriate.

In this sense, the dispute over KR principle involves theories according to which we can know things without knowing that we know and theories according to which we can't know without knowing that we know.

If that is right, what Cohen calls KR principle could be seen as the pyrrhonian assumption that poses the problem of the criterion. If the problem of the criterion is "a meta-epistemological problem concerning the justification of first order knowledge claims among disagreeing disputants", ${ }^{17}$ the KR principle seems to be a clear way to make this disagreement explicit. In other words, when disputants disagree about the justification of first-order knowledge claims, they disagree over the acceptance of a principle like $\mathrm{KR}$.

It seems quite patent, then, that KR Principle and problem of the criterion have a meta-epistemological nature. The problem of the criterion is a meta-epistemological problem, in the sense that it is not a problem about whether we can know but rather it is a problem about whether we can justify our first-order knowledge claims.

This important feature of the problem of the criterion was made clear by Chisholm, when he revitalized it in contemporary epistemology some years ago. As it was considered in the pyrrhonian tradition, Chisholm describes the problem of the criterion as one concerning "decisions". According to him, the problem of the criterion was "how do we decide, in any particular case, whether we have a genuine item of knowledge?"18. The problem of the criterion is not about the specification of the necessary

16 Cf. Alvin Goldman, Epistemology and Cognition, p. 56.

17 Cf. Roberto Amico, The Problem of the Criterion, p. 143.

18 Cf. Roderick Chisholm, The Foundations of Knowing, p. 62. 
and sufficient conditions for knowing. Again, the trouble is rather about whether we can know that we know.

After all, the meta-epistemological nature of the problem of the criterion and, consequently, of the bootstrapping problem-given that the former seems to be a predicament derived from an alternative response to the problem of the criterion - is in perfect harmony with the original inspiration of the criticism against reliabilism. For Vogel, for example, "[a form of reliabilism that he called Neighborhood Reliabilism] is too weak. It would allow us higher-level knowledge we do not have". ${ }^{19}$ If this is right, the bootstrapping problem must be understood as the problem of the easiness of a certain strategy of acquiring second-order knowledge.

So, it is correct to say that bootstrapping problem is a consequence of a certain strategy to deal with the problem of the criterion. More specifically, and using Cohen's terms, the bootstrapping problem is a consequence of trying to resolve the problem of the criterion avoiding the KR principle by means of a basic knowledge structure view.

In this sense, the problem with bootstrapping emerges when using a certain strategy to resolve a second-order problem, which could be well represented by the knowledge of the reliability of a knowledge source, provided that knowing the source used to come to know a proposition $p$ is reliable means knowing that we know $p$.

When we bootstrap we manage a certain way to come to know that we know - e.g. to come to know we use a reliable process. The relation between the bootstrapping problem and the problem of the criterion is fruitful because it reassures the meta-epistemological character of the problem of easy knowledge. Out of this relation we can then better understand what kind of knowledge is easy knowledge.

In order to notice why bootstrapping is a strategy to deal with the problem of the criterion, we have to understand what is the pyrrhonian view on bootstrapping.

According to Sextus:

"For the proof always requires a criterion to confirm it, and the criterion also a proof to demonstrate its truth; and neither can a proof be sound without the previous existence of a true criterion nor can the criterion be true without the previous confirmation of the proof. So in this way both the criterion and the proof are involved in the circular process of reasoning." 20

Granted, we can't accept anything when its proof hangs on circular reasoning. And what seems to be the main problem here is the impossibility of establishing a criterion using whatever the criterion itself proves to be

19 Cf. Jonathan Vogel, Reliabilism Leveled, in: Journal of Philosophy, p. 612.

20 Cf. Sextus Empiricus, Outlines of Pyrrhonism, 1.114-117. 
the case. To judge our knowledge claims, we ought to have a criterion - in order to know whether the belief B is a genuine item of knowledge, we need a criterion according to which we will decide such matter. We can know that we know $p$ if we know that the belief formation process is in fact reliable. But how do we know the belief formation process is in fact reliable? If we answer this question pointing out the belief $\mathrm{B}, \mathrm{a}$ belief that is sanctioned by the criterion as a case of knowledge, we will be caught into the diallelus.

On the other hand, the typical circular reasoning is meant to be close up under the same epistemic level (as it is showed, for example, by another pyrrhonian argument, Agripa's trilemma or the infinite regress argument). The main idea of Agripa's trilemma is that in order for $S$ to have justification to believe B on the basis of a reason $\mathrm{R}, S$ will also have to have justification to believe $R$. Granted, $B$ and $R$ must be related in a very distinctive form so $\mathrm{R}$ can be a proper epistemic ground for $\mathrm{B}$. Yet nothing is said, at least in this kind of regress, about the necessity for $S$ to have any reason to believe that $\mathrm{R}$ confers a proper epistemic ground for B.

The circle shaped by Agripa's trilemma materializes when I use a reasoning that goes like this: my justification to believe $B$ is $R$; my justification to believe R is $S$ and my justification to believe $S$ is B. This way I'm looping inside the same epistemic level.

In the bootstrapping case, the kind of circularity involved has to do with proving the reasons used are appropriate, and in this way we jump up between levels. In this meta-regress, I use my belief $B$, which is epistemically grounded by my other belief $R$, to prove that $R$ is a proper epistemic base for B.

As it looks, there are two types of circular reasoning, a first-order circular reasoning and a second-order circular reasoning. In order to understand the difference between them we have to remember the epistemological level distinction. Albeit both types have the same characteristic of avoiding the onus of proving the premise basing it on the previous acceptance of the conclusion - what makes them fallacies of petitio principii - the result of each circular reasoning will change. In one case, my belief $B$ is part of a reasoning chain that justifies $B$ itself; in another case, $B$ is used in a reasoning chain that is intended to demonstrate that the grounds for $B$ are epistemically suitable. In one case B is used to provide justification for itself; in the other, B is used to provide meta-justification for itself.

The circular reasoning that has to do with the problem of criterion and, hence, bootstrapping - is, lets say, vertical. It relates to a movement from first to second level. In this form of circular reasoning the circle goes 
from first to second level, and we try to establish that we have a genuine item of knowledge using a criterion that is proved by a knowledge (claim) that was, in turn, legitimated by the criterion itself.

This significant difference about the two types of circularities is not detected by Sextus. That's why he is one source for level confusion. Even though he provides, two distinct arguments, he fails to notice the difference - at least, he falls short of making it unambiguous.

A different way to understand these two different circular reasoning is to consider Fumerton's Principle of Inferential Justification (PIJ): to be justified in believing one proposition $p$, on the basis of another proposition $\mathrm{E}$, one must be (1) justified in believing $\mathrm{E}$ and (2) justified in believing that $\mathrm{E}$ makes probable $p .{ }^{21}$

There would be many things to say about this principle. However, the idea now is just to give an example of how create two different kinds of epistemic regresses that, by consequence, can create two different kinds of circular reasoning.

According to PIJ, in order to have an appropriate evidence to believe $B$, or to have justification to believe $B$, we must have to deal with two different chains of reasoning: one implied by the first clause, that will trigger a first-order regress, and another implied by the second clause, that will start a second-order, or meta-regress.

One noticeable aspect of PIJ is that it requires meta-justification as a condition for first order justification. Thus, in order to have justification to believe B we'll altogether need some sort of meta-justification for B.

The first clause of PIJ triggers a chain of reasoning such as Agripa's trilemma. In order to have a justified belief that owes its justification to some reason - or evidence, etc. - we'll be forced to go further ad infinitum, or reasoning in a circle, or stopping at a certain point. All of these possibilities, though, are inserted in the same epistemic level.

The second clause, however, sets off a slightly different array of possibilities. The type of regress we deal with then, the regress of metajustification, forces us not to put forward reasons for the beliefs we have, but reasons for the epistemic quality of our reasons.

Thus, in the same way we can create either an infinite, more complex, regress of meta-justification or an infinite, less complex, regress of justification, we can create either a circular reasoning of justification or a circular reasoning of meta-justification. Again, in one case we are offering reasons to believe a certain proposition; in the other we are presenting a reason that we do have good reasons to believe what we believe.

${ }^{21}$ Cf. Richard Fumerton, Metaepistemology and Skepticism, p. 36. 
So, what has been called "bootstrapping" is but an attempt to justify knowledge claims through a form of a circular reasoning that switches from the first to the second epistemic level. That's why bootstrapping is one strategy - unacceptable for both Cohen and the pyrrhonians - to deal with the problem of the criterion. Of course, any explanation we may find of bootstrapping is much sharper and sophisticated than anything we can find in Sextus Empiricus. Then again, this does not opaque the fact that circular reasoning for the problem of the criterion and bootstrapping are the same thing.

On the same token, what Cohen calls easy, the pyrrhonian see as plainly inadequate. The only way to understand the meaning of "easy knowledge" is that it designates the inappropriateness of one sort of knowledge acquisition. The idea of "easy knowledge" hides the conception that this "easy" means "too easy," "unbearably easy." In one word, "unacceptable."

Summing things up: when we talk about the reliability of a belief process formation, we could bootstrap in order to come to know that the process is reliable; when we talk about reasons, we could bootstrap in order to come to know that we have adequate reasons to believe the things we do. In both cases the problem seems to reside on the limitation of the requirements of what would be necessary in order to be justified in believing some proposition. Exactly because it is not required for $S$ to have any clue about the epistemic quality of the reasons (or methods) she uses to believe the things she does, she will be able to use the epistemic good (or bad!) resultant beliefs she has to prove the epistemic quality of the reasons or (methods) she uses to believe. And this may be done independently of the fact that the reasons are adequate or the methods are reliable. That's the problem with what Cohen calls basic knowledge structure views. The skeptical conclusion would be that just a reliable method, or just a proper reason, seems not to be enough to deliver justified beliefs.

Whether we talk about either reasons or methods of belief formation, we will be trapped into a circular form of reasoning that establishes unacceptable bridges between first and second epistemic levels.

There are a number of forms to manifest dissatisfaction with this kind of restrictions. I think it is exactly what Lehrer was saying with "examples of alleged knowledge in which a person does not know that the information he accepts is correct my be of some philosophical interest but such knowledge falls outside the concern of knowledge used in a way that is characteristically human in critical reasoning and the life of reason". ${ }^{22}$

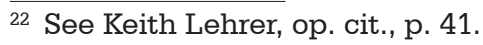


In some sense, the problem of the criterion and bootstrapping can be seen as demonstrating what is wrong with this sense of "knowledge" when the person ignores the information accepted is correct - or ignores that the reason is epistemically good, or that the process is reliable. ${ }^{23}$

I'll repeat, it doesn't matter if the processes are in fact reliable or if the reasons are in fact good. One could think that using the results of some process to prove the reliability of it is legitimate just in case the process is in fact reliable. Such strategy fails because it is in itself inadequate, and this is so because such a strategy is trivial, it will always give the same result: the processes are reliable, even when they aren't.

So, this is the problem of bootstrapping. There are theories that independently of their internalistic or externalistic brand will face the problem of allowing this kind of meta-circularity, the bootstrapping strategy, and bootstrapping has to do with acquiring second-order knowledge through a form of reasoning that inadequately connects first and second epistemic levels.

If we think about Goldman's suggestion that "a plausible theory ought to have the property that knowing that one knows is more difficult than simply knowing", ${ }^{24}$ we will find bootstrapping, or circular reasoning, as a way to make second-order knowledge somehow less difficult than first-order knowledge.

\section{Conclusion}

One optimistic way to describe what we have seen would be to say something like this: instead of one problem that emerges in two different forms, Cohen has two quite different problems at stake when he discusses the easy knowledge problem. One of them is the meta-epistemological question posed by the $\mathrm{KR}$ principle, which is represented by the inadequate acquisition of reliability knowledge through bootstrapping. The other is the supposedly inadequate knowledge acquired through the closure principle.

Accordingly, the difference between closure and bootstrapping is a fundamental one: closure does not motivate any "easy" secondorder knowledge acquisition. He apparently failed to notice that there exist two different things subsumed in what he called "the problem of easy knowledge." Differently from closure, bootstrapping is a way to

${ }^{23}$ I guess to Lehrer the question is a bit different, since he seems to reject the very idea that we could gain knowledge in the way described: "if I read some gauge or meter and believe the information I received, though I have no idea whether the instrument is functioning properly, I may thus acquire information, but this is not knowledge." See Keith Lehrer, op. cit., p. 6.

24 See Alvin Goldman, op. cit., p. 57. 
come to know that our belief sources are reliable, that our reasons are epistemically appropriate. Then, it has a meta-knowledge nature. This difference is crucial.

The closure principle does not motivate any easy knowledge problem as bootstrapping does. In the worst hypothesis, closure is related to the problem of deciding if we can reason like this: it seems red, thus it is red. Bootstrapping, on the other hand, is related to the problem of coming to know that we know in a way in which we can reach the conclusion that we know that we know even if we do not know in the first place. Those are quite different problems.

Cohen - and many epistemologists after him - does not observe the important difference between the two supposed ways in which the problem of easy knowledge arises. He didn't notice that there exists a difference regarding epistemic levels. If this is right, there is some level confusion lurking in his talk about the easy knowledge problem. He should have observed that there were two different problems - one related to the easy acquisition of first-order knowledge by closure, and the other one related to the easy acquisition of second-order knowledge by bootstrapping - that require two quite different analyses.

On a less optimistic description - the one I think is correct - we'll have to say that there is no easy knowledge problem. To begin with, there is no problem at all with the closure principle. Thus, the closure principle does not motivate any easy knowledge problem. The real problem Cohen is dealing with is to decide - how, how much, to what extent, etc. the appearances of things can be the base for our knowledge of the world.

In the bootstrapping case, Cohen is, again, battling against a very old and complicated problem: namely, the problem of the criterion. However, differently from the case about the closure principle, his description of the problem seems to be quite interesting. Nevertheless, he is mistaken to imagine a new problem, the easy knowledge problem.

\section{References}

ALSTON, William. "Level Confusions in Epistemology". In: Midwest Studies in Philosophy, 5 (1980), p. 135-150.

AMICO, Roberto. The Problem of the Criterion. Boston: Rowman-Littlefield, 1995.

Black, Tim. "Solving the Easy Knowledge Problem". In: The Philosophical Quarterly, 58 (2008), p. 597-617.

CHISHOLM, Roderick. The Foundations of Knowing. Minneapolis: University of Minnesota Press, 1983.

COHEN, Stewart. "Basic Knowledge and the Problem of Easy Knowledge". In: Philosophy and Phenomenological Research, 65 (2002), p. 309-329. 
. "Why Basic Knowledge is Easy Knowledge". In: Philosophy and Phenomenological Research, 70 (2005), p. 417-430.

DRETSKE, Fred. Perception, Knowledge and Belief. Cambridge: Cambridge University Press, 2000.

FLORES, Tito. "Infinitism, Knowing that one Knows and the Problem of the Criterion". In: Veritas, 50 (2005), p. 109-128.

FUMERTON, Richard. Metaepistemology and Skepticism. Maryland: Rowman and Littlefield, 1995.

GOLDMAN, Alvin. Epistemology and Cognition. Cambridge: Harvard University Press, 1986.

KLEIN, Peter. "Closure Matters: Academic Skepticism and Easy Knowledge". In: Philosophical Issues, 14 (2004), p. 165-181.

. "Human Knowledge and the Infinite Regress of Reasons". In: TOMBERLIN,

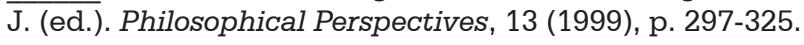

LEHRER, Keith. Theory of Knowledge. Boulder: Westview Press, 2000.

MARKIE, Peter. "Easy Knowledge". In: Philosophy and Phenomenological Research, 70 (2005): 2, 406-416.

NETA, Ram. "A Contextualist Solution to the Problem of Easy Knowledge". In: Grazer Philosophische Studien: Internationale Zeitschrift für Analytische Philosophie, 69 (2005), p. 186-206.

Sextus Empiricus. Outlines of Pyrrhonism. 4 v. Translated and Edited by R. G. Burry. Cambridge: Harvard University Press, 1935.

VOGEL, Jonathan. "Reliabilism Leveled". In: Journal of Philosophy, 97, (2000), p. 602-623.

WILLIAMS, Michael. Unnatural doubts. Oxford: Blackwell, 1991.

VAN CLEVE, James. "Is Knowledge Easy - or Impossible? Externalism as the Only Alternative to Skepticism". In: LUPER, Steven (ed.). The Skeptics: Contemporary Essays. Aldershot, UK: Ashgate Publishing, Ashgate Epistemology \& Mind Series, 2003, p. 45-49. 